\title{
The university workers' willingness to pay for commuting
}

\author{
Giovanni Russo $\cdot$ Jos van Ommeren • Piet Rietveld
}

(C) The Author(s) 2012. This article is published with open access at Springerlink.com

\begin{abstract}
Using a dynamic approach, employing data on job mobility, we demonstrate that university workers' marginal willingness to pay for reducing commuting distance is about $€ 0.25$ per kilometre travelled. This corresponds to a marginal willingness to pay for reducing commuting time of about $75 \%$ of the net average hourly wage. For females, the willingness to pay is substantially higher than for males. It is also substantially higher for workers that work few hours per day, as predicted by theory.
\end{abstract}

Keywords University · Workers · Commute - Willingness to pay

\section{Introduction}

It is common to estimate the workers' cost of commuting using stated preference approaches (e.g. De Borger and Fosgerau 2008). In the current paper, we aim to estimate the workers' cost of commuting using a dynamic methodology approach that uses revealed preference data. We derive this cost from the ratio of the (estimated) effects of commuting distance and wages on workers' job quitting behaviour. We apply this approach to university workers. Our methodology avoids the assumption of a competitive labour market. This is important in the context of workers employed by universities, which have been shown to have monopsony power (Ransom 1993; Barbezat 2004). In particular, faculty workers, so those involved in teaching and research, face relatively large job search cost as they usually have only few other nearby employment alternatives.

\author{
G. Russo \\ Cedefop, PO Box 22427, Finikas, 55102 Thessaloníki, Greece \\ e-mail: giovanni.russo@cedefop.europa.eu \\ G. Russo \\ IZA, Bonn, Germany \\ J. van Ommeren $(\varangle) \cdot$ P. Rietveld \\ VU University, Amsterdam, The Netherlands \\ e-mail: jos.van.ommeren@vu.nl
}


For a competitive labour market, it is appropriate to estimate the workers' cost of commuting using a hedonic wage approach. This approach essentially regress wages on the length of the commute are widely applied (e.g. Zax 1991). However, this approach has been shown to induce biased estimates of the effect of commuting costs on wages, in particular in environments where workers search for other jobs (Hwang et al. 1992, 1998; Gronberg and Reed 1994). This is even more true for organisations operating in institutional environments where wages are regulated such as for universities, so wages of university workers will usually hardly respond to the length of the commute. So, hedonic wage approaches are an unattractive method to estimate the willingness to pay for commuting, at least for university workers.

In the current paper, we apply a dynamic methodology based on job mobility information. Compared to previous studies that use a similar dynamic methodology (e.g. Manning 2003a, 2003b; van Ommeren and Fosgerau 2009), our application offers two methodological advantages. First, we focus on workers from one university. These workers share the same workplace location, so many-difficult to observe-differences related to employer' industry and workplace location are controlled for (see, Zax 1991; Villanueva 2007; Gruetter and Lalive 2009). Second, we use administrative data that contain detailed information about wages, so we largely avoid the measurement-in-wage problem, common in survey data, which biases the estimates (Van Ommeren and Hazans 2008). In the context of commuting, it is important that our administrative data are also informative about the presence of other transport-related fringe benefits (monetary travel subsidies, on-site parking permits) that determine largely the monetary cost of commuting, and precise information about jobs (the type of function, career opportunities). This type of information is usually missing in survey data. Third, we have rather precise information about the hours worked per day (as well as number of days per week). This is relevant as labour supply theory predicts that workers with few daily work hours have a higher time cost of commuting, because of higher opportunity costs of time (Manning 2003a). This may explain why (female) workers with few daily working hours commute less. The relationship between labour supply and commuting has received much attention in the transport economics literature (Parry and Bento 2001; Arnott 2007; Gutiérrez-i-Puigarnau and van Ommeren 2010).

The structure of the paper is the following: Sect. 2 provides the theoretical methodology to derive workers' willingness to pay for commuting time. Section 3 contains the data description. The empirical analysis is presented in Sect. 4, while Sect. 5 offers concluding remarks.

\section{Theory}

In the current paper, we will use a dynamic search methodology approach to identify workers' willingness to pay for job attributes (e.g., commuting time), introduced in the seminal paper by Gronberg and Reed (1994). ${ }^{1}$ It is essentially assumed that employed workers have to search for other jobs that are offered with a certain probability given an endogenously chosen search effort. Each worker has a job which provides a wage and job attributes and workers know the distribution of wages and job attributes of other jobs. Given an offer, workers have to accept or reject jobs.

\footnotetext{
${ }^{1}$ We follow Van Ommeren and Fosgerau (2009) who have extended this approach by relaxing some of the underlying assumptions. For empirical applications, see, among others, Manning (2003a, 2003b), DaleOlsen (2006) and Isacsson and Swärdh (2007).
} 
The main idea of this approach is to use information about employees' job quitting behaviour (or job search behaviour). Given stationarity assumptions on the search environment, the employees' marginal willingness to pay for a job attribute is then obtained from the ratio of the marginal effect of the job attribute on the probability to quit and the marginal effect of the wage on the probability to quit (Van Ommeren and Fosgerau 2009). More formally,

$$
M W P_{x} \equiv \frac{\partial v / \partial x}{\partial v / \partial w}=\frac{\partial \operatorname{Pr}(\text { job quit })}{\partial x} / \frac{\partial \operatorname{Pr}(\text { job quit })}{\partial w},
$$

where $\mathrm{MWP}_{x}$ is the workers' marginal willingness to pay for attribute $x, v$ is the workers' current utility of a job, which is a function of job attribute $x$ and wage $w(\partial v / \partial w>0)$, and $\operatorname{Pr}$ (job quit) denotes the probability that a worker voluntarily leaves the organization. This result is intuitive: employees attach a certain (dis)utility to job attributes as well as to wages, which is revealed through the likelihood that employees quit if workers are confronted with a marginal change in $w$ and $x$. We will now focus on one job attribute: commuting time.

To estimate (1), one has to put some restrictions on the functional form of $\operatorname{Pr}($ job quit). If it is assumed that $\operatorname{Pr}($ job quit $)=f\left(\beta_{x} \log x+\beta_{w} \log w\right)$, where $\beta_{x}$ and $\beta_{w}<0$ are parameters to be estimated, $\log x$ is the logarithm of commuting time $x, \log w$ is the logarithm of $w$, and $f$ is an arbitrary continuous function (increasing in its argument), then:

$$
M W P_{x}=\frac{\beta_{x}}{\beta_{w}} \frac{w}{x} .
$$

Hence, to derive $\mathrm{MWP}_{x}$ and therefore the workers' cost of commuting, it is sufficient to obtain estimates of $\beta_{x}$ and $\beta_{w}$.

The above specification of $f$ ignores interaction effects between commuting time and other variables. According to theory, the length of the working day is important, because the $\mathrm{MWP}_{x}$ is proportional to the inverse of the daily hours of work, denoted by $h$ (see, Manning 2003a). This is intuitive as workers with few working hours per day apparently have high opportunity costs of working. To capture this, we include also the ratio of log distance and daily hours in $f$, so $\operatorname{Pr}($ job quit $)=f\left(\beta_{x} \log x+\beta_{x h} \log x / h+\beta_{w} \log w\right)$, where $\beta_{w}<0$ and $\beta_{x}+\beta_{w} / \mathrm{h}<0$. The $\mathrm{MWP}_{x}$ must be changed accordingly and now it reads as follows:

$$
M W P_{x}=\frac{\beta_{x}}{\beta_{w}} \frac{w}{x}+\frac{\beta_{x h}}{\beta_{w}} \frac{w}{x h} .
$$

So, to estimate $\mathrm{MWP}_{x}$, one must estimate $\beta_{x}, \beta_{w}$, and $\beta_{x h}$. We emphasise that in our setup, we assume that the worker's residence location is given (this assumption may be relaxed, see Van Ommeren et al. 2000) and that workers with long commutes may receive compensation in the housing market. So, the worker's cost related to commuting refer here to the worker's cost in addition to any compensation received in the housing market.

This dynamic approach may be compared to the main alternative approach, the hedonic wage approach, which essentially regresses the wages on the length of the commute. The hedonic wage approach is particularly suitable in non-regulated labour markets. However, for professions where wages are highly regulated, such as at the university, the dynamic approach is likely a better estimation approach. 


\section{Data description}

We focus on employees of the VU University, which is located at the edge of Amsterdam in the "Zuidas" area, one of the most expensive office locations in the Netherlands. ${ }^{2}$ All employees work at the same workplace location. One of the main characteristics of this location, relevant to the current empirical application, is that it is at a few-minutes walking distance from a train station, at cycling distance from the city centre of Amsterdam and only a couple of minutes drive from a major, although heavily congested, highway.

We use detailed annual administrative data for employees who are younger than the compulsory retirement age (65 years), to limit the impact of involuntary transitions into retirement, and who are on a permanent contract. As the involuntary quit rate of personnel on permanent contracts is negligible, we may safely assume that all quits are voluntary, as required by the theoretical framework detailed in Sect. 2. The data provide information about the employment contract (and other variables) on the first of February in the years 2003 until 2010. ${ }^{3}$ Given these data, we are able to calculate for each year whether an employee quits the university. ${ }^{4}$ In total, we have 19,554 annual observations (with information about quitting behaviour) for 5,303 employees. On average, each employee is about four times observed. We observe about 2,500 quits. The average annual quit rate is 12.4 percent.

We have information on a range of workers' characteristics: age, commuting distance, gender and hourly gross wage. For descriptive information, see Appendix Table 2. ${ }^{5}$ Unfortunately, we do not have other socio-economic characteristics (such as children), but as these characteristics are usually not strongly related to job quitting behaviour, the potential bias of not having this information should be minor. Most studies focus on wages to derive the workers' marginal willingness to pay but one may also use other monetary job attributes. In the university we focus on, workers who travel by public transport receive a reimbursement of about 50 to $70 \%$ of the monetary travel expenses, whereas other workers, if the commuting distance exceeds $10 \mathrm{~km}$, so mainly those who travel by car receive a reimbursement of $€ 0.04$ per one-way km per day, up to a maximum of $€ 65$ per month. Because this reimbursement is small relative to the salary, about $4 \%$ of the gross wage, we have included it in the gross wage. Distinguishing between these monetary components does not change the results.

Furthermore, we use weekly hours and number of days worked per week as control variables. ${ }^{6}$ We also use information on daily hours worked which we use to interact with commuting distance. We derive average daily hours by dividing weekly hours by number of workdays. This creates some measurement error, because for some workers daily hours

\footnotetext{
${ }^{2}$ We believe the choice of an expensive area has been accidental. When the VU university was established, this area was not expensive and not well connected to public transport. Nowadays, this area contains many (international) law firms, headquarters of banks etc.

3 We exclude few observations with a commute longer than $150 \mathrm{~km}$, a commuting reimbursement above $20 \%$ of the salary, daily working hours less than 1.5 or in excess of 10 or a hourly wage above $€ 100$.

4 The 2010 wave is merely used to determine quits. So, the dummy variable quit $t_{i t}$ is 1 when worker $i$ is observed in wave $t$ but not in wave $t+1$.

5 We do not have this information for other university workers in the Netherlands, but as the university labour market is quite regulated, there are relatively small differences between universities in terms of types of contract, wages etc. However, the level of commuting reimbursement and transport mode are idiosyncratic to each university.

${ }^{6}$ Using daily hours rather than weekly hours or number of days worked per week generates identical results to the results presented here.
} 
vary per day of the week (e.g., they work 4 days $8 \mathrm{~h}$ and one day $4 \mathrm{~h}$ ). For the last two waves of the sample, we have detailed information on the exact number of hours worked per day of the week. It appears that only $8 \%$ of workers vary daily hours over the week. Thus, the average number of daily hours is a rather accurate measure. ${ }^{7}$

Administrative data usually do not contain information about workers' educational level. Fortunately, the university's personnel files contain information about the workers' academic title. We were thus able to infer educational level, distinguishing between workers without university degree, with a Master degree or a $\mathrm{PhD} .^{8}$

We know workers' job title, which allows us to distinguish between faculty members, academic support staff (teaching and research support functions, including student relations) and administrative staff. ${ }^{9}$ Parking at parking spaces provided by the University requires a parking permit. We have (although not complete) information about (the use and eligibility of) parking permits, which we use as a control variable. Parking permits are provided to eligible employees (at a cost of less than $€ 1$ per day), but as only $30 \%$ of the employees who are eligible apply for it, the policy is not restrictive for eligible workers. ${ }^{10}$ We also control for the use of public transport. ${ }^{11}$ These data indicate that at least half of workers commute by bicycle.

We also control for recent promotions. This is relevant in a search context but usually difficult to control for. We are able to do so, because the wage policy of the university is based on ten broad wage scales; wage scales are further subdivided into maximally 12 steps. Advancement within a scale is, almost always, automatic: one step per year. Advancement between scales, however, is not automatic: passage onto the next wage scale is conditional on a successful job evaluation. Hence, each progression in scale implies a promotion. $^{12}$

In addition, we aim to control for the lack of promotion opportunities. Normal career progression entails that workers move to the next scale when they are between the 5th and 7th step. Hence, most workers that are relatively high up in the step level are either less productive than it may have been expected a priori or have attained a scale level such that promotions are difficult to realise within the university. In particular, workers at the very top of the scale are likely to have been passed on for promotion many times in a row, and it is thus very unlikely that they will be promoted in the future. Since the lack of promotion possibilities will affect the workers' expectation of wage increases with the current employer, we have included a dummy variable signalling when a worker is at the top of the scale (e.g. step 10-12).

\footnotetext{
7 We also lack information about the start time (see Gutiérrez-i-Puigarnau and van Ommeren 2012). However, as a rule, most workers and in particular faculty workers are quite flexible regarding start time.

${ }^{8}$ We also know if the field of study was technical (i.e., engineering) or law, but distinction by field appeared not to be relevant for the results presented.

9 Faculty members, academic support and administrative staff represent respectively 26,17 , and $57 \%$ of the workforce on a permanent contract.

${ }^{10}$ Eligibility depends on the ratio of car and public transport travel times. In addition, some parking permits are allocated by faculties. Unfortunately we were not able to recover complete information on permits allocated by faculties as information for the first years of our sample was particularly poor.

11 Information about public transport is derived from annual commuting reimbursements that depend on the mode of transport. Probably this understates public transport use by several percentage points. Company cars are important fringe benefits in the Netherlands (Gutiérrez-i-Puigarnau and van Ommeren 2011), but not provided by public organisations such as universities.

12 The dummy variable promotion $_{i t}$ is 1 when workers $i$ is observed in wage scale $H$ in $t-1$ and in wage scale $H+1$ (or higher) at time $t$.
} 
We emphasise that we do not control for house prices or other quality indicators of housing (which may, maybe partially, compensate for the length of the commuting distance). So, we estimate the workers' marginal willingness to pay for commuting in addition to any compensation received in the housing market (e.g., those with a longer commute may have a lower house price). Note that when house prices fully compensate for the length of the commuting distance, then workers at different residence locations are equally well off. In this case, the probability of leaving the university will not depend on the length of the commuting distance. When house prices do not fully compensate for the incurred commuting costs, workers with a long commute are less well off, and are more likely to leave their job.

In our data, the average one-way commuting distance of workers is $22 \mathrm{~km}$, so the daily commuting distance travelled is $44 \mathrm{~km} .{ }^{13}$ The average full-time equivalent gross yearly wage is $€ 47,665$, above the average gross salary of Dutch workers (about $€ 32,000$ ). The average gross hourly wage is $€ 26.5$, which amounts to an average gross daily wage of $€ 212$. Most workers face a marginal income tax rate of about $50 \%$, consequently the net average daily wage is about $€ 106$ and the net hourly wage is just above $€ 13$. Summary statistics of other variables used in the analysis are provided in the Appendix Table 2.

\section{Empirical analysis}

To estimate the workers' marginal willingness to pay for commuting time, we have estimated the workers' probability to quit, using a worker random effects logit model (Model 1). The results are presented in Table 1 in columns 1 (coefficients) and 2 (marginal effects). It appears that the effect of the ratio of commuting distance and daily hours variable is positive ( 0.844 with a standard error of 0.444$)$, although it is imprecisely estimated. The effect of commuting distance itself is highly insignificant ( $t$ value is 0.15 ): so the overall effect of distance is almost entirely captured by the ratio of commuting distance to daily hours. Because a standard likelihood ratio test shows that both distance variables are jointly highly significant $\left(\chi^{2}(2)=12.42\right)$, we present the results of a model that only includes the distance to daily hours variable (Model 2). This is equivalent to setting $\beta_{x}=0$ so that the entire first term in equation (3) equals zero. The difference in the $\log$ likelihood of both models is trivial and in terms of interpretation the results are identical.

We find a negative effect of wage, $\beta_{w}=-1.216$ (s.e. 0.169), whereas the effect of the ratio of commuting distance to daily hours, $\beta_{x h}$, is positive $(0.889$ with a standard error of 0.219). ${ }^{14}$ This implies that the workers' willingness to pay to avoid a longer commute is decreasing in daily working hours, in line with Manning (2003a). The specification implies that the $\mathrm{MWP}_{\mathrm{x}}$ for a full-time worker who works $8 \mathrm{~h}$ a day is half the $\mathrm{MWP}_{\mathrm{x}}$ for a parttime worker who works only $4 \mathrm{~h}$ a day. ${ }^{15}$

\footnotetext{
${ }^{13}$ In the Netherlands, the average one-way commuting distance is about $17 \mathrm{~km}$, but $21 \mathrm{~km}$ among workers with university degrees.

${ }^{14}$ We have also estimated models including a quadratic term in log wage. Although the quadratic term appears slightly positive, within the relevant wage range, the marginal effect of wages on the probability to quit is negative.

15 The coefficient on distance remains positive and significant also when wage is not included in the quit regression, which implies that workers are not fully compensated for their commuting losses in the labour and housing market (Manning, 2003a; Stutzer and Frey, 2008).
} 
Table 1 Random effects logit estimates of the probability to quit

\begin{tabular}{|c|c|c|c|c|}
\hline \multirow[t]{2}{*}{ Dependent variable: quit } & \multicolumn{2}{|l|}{ Model 1} & \multicolumn{2}{|l|}{ Model 2} \\
\hline & Coefficients & Marginal effects & Coefficients & Marginal effects \\
\hline Log wage & $\begin{array}{r}-1.216^{*} \\
(0.169)\end{array}$ & $\begin{array}{c}-0.105^{*} \\
(0.015)\end{array}$ & $\begin{array}{r}-1.216^{*} \\
(0.169)\end{array}$ & $\begin{array}{c}-0.105^{*} \\
(0.015)\end{array}$ \\
\hline Log distance & $\begin{array}{c}0.010 \\
(0.074)\end{array}$ & $\begin{array}{c}0.001 \\
(0.006)\end{array}$ & & \\
\hline Log distance/daily hours & $\begin{array}{c}0.844 \\
(0.444)\end{array}$ & $\begin{array}{c}0.073 \\
(0.038)\end{array}$ & $\begin{array}{c}0.898 * \\
(0.219)\end{array}$ & $\begin{array}{c}0.078 * \\
(0.019)\end{array}$ \\
\hline No promotion opportunities & $\begin{array}{c}0.154 * \\
(0.076)\end{array}$ & $\begin{array}{c}0.013 * \\
(0.007)\end{array}$ & $\begin{array}{c}0.154 * \\
(0.076)\end{array}$ & $\begin{array}{c}0.013 * \\
(0.007)\end{array}$ \\
\hline Recent promotion & $\begin{array}{c}-0.682 * \\
(0.108)\end{array}$ & $\begin{array}{c}-0.059 * \\
(0.009)\end{array}$ & $\begin{array}{c}-0.682 * \\
(0.108)\end{array}$ & $\begin{array}{c}-0.059 * \\
(0.009)\end{array}$ \\
\hline Public transport & $\begin{array}{c}-0.427^{*} \\
(0.085)\end{array}$ & $\begin{array}{c}-0.037 * \\
(0.007)\end{array}$ & $\begin{array}{c}-0.425^{*} \\
(0.082)\end{array}$ & $\begin{array}{c}-0.037 * \\
(0.007)\end{array}$ \\
\hline Parking permit & $\begin{array}{r}-0.107 \\
(0.156)\end{array}$ & $\begin{array}{r}-0.009 \\
(0.013)\end{array}$ & $\begin{array}{r}-0.105 \\
(0.155)\end{array}$ & $\begin{array}{r}-0.009 \\
(0.013)\end{array}$ \\
\hline \multicolumn{5}{|l|}{ Work hours } \\
\hline Hours worked per week/38 & $\begin{array}{c}1.098 * \\
(0.498)\end{array}$ & $\begin{array}{c}0.095^{*} \\
(0.043)\end{array}$ & $\begin{array}{c}1.140 * \\
(0.397)\end{array}$ & $\begin{array}{c}0.099 * \\
(0.034)\end{array}$ \\
\hline 1 day per week & $\begin{array}{c}1.939 * \\
(0.394)\end{array}$ & $\begin{array}{c}0.168 * \\
(0.034)\end{array}$ & $\begin{array}{c}1.968 * \\
(0.332)\end{array}$ & $\begin{array}{c}0.170 * \\
(0.029)\end{array}$ \\
\hline 2 days per week & $\begin{array}{c}1.452 * \\
(0.317)\end{array}$ & $\begin{array}{c}0.126^{*} \\
(0.027)\end{array}$ & $\begin{array}{c}1.475^{*} \\
(0.268)\end{array}$ & $\begin{array}{c}0.128 * \\
(0.023)\end{array}$ \\
\hline 3 days per week & $\begin{array}{c}0.912 * \\
(0.220)\end{array}$ & $\begin{array}{c}0.079 * \\
(0.019)\end{array}$ & $\begin{array}{c}0.928 * \\
(0.186)\end{array}$ & $\begin{array}{c}0.080^{*} \\
(0.016)\end{array}$ \\
\hline 4 days per week & $\begin{array}{c}0.302 * \\
(0.123)\end{array}$ & $\begin{array}{c}0.026 * \\
(0.011)\end{array}$ & $\begin{array}{c}0.310^{*} \\
(0.108)\end{array}$ & $\begin{array}{c}0.027 * \\
(0.009)\end{array}$ \\
\hline \multicolumn{5}{|l|}{ Education } \\
\hline Master degree & $\begin{array}{r}-0.514^{*} \\
(0.102)\end{array}$ & $\begin{array}{c}-0.045^{*} \\
(0.009)\end{array}$ & $\begin{array}{c}-0.514 * \\
(0.101)\end{array}$ & $\begin{array}{c}-0.044^{*} \\
(0.009)\end{array}$ \\
\hline No university degree & $\begin{array}{c}-0.857 * \\
(0.127)\end{array}$ & $\begin{array}{c}-0.074 * \\
(0.011)\end{array}$ & $\begin{array}{c}-0.856^{*} \\
(0.127)\end{array}$ & $\begin{array}{c}-0.074^{*} \\
(0.011)\end{array}$ \\
\hline \multicolumn{5}{|l|}{ Type of job } \\
\hline Faculty & $\begin{array}{r}-1.340 * \\
(0.115)\end{array}$ & $\begin{array}{r}-0.116^{*} \\
(0.010)\end{array}$ & $\begin{array}{c}-1.339 * \\
(0.115)\end{array}$ & $\begin{array}{r}-0.116^{*} \\
(0.010)\end{array}$ \\
\hline Administrative & $\begin{array}{r}-0.718^{*} \\
(0.097)\end{array}$ & $\begin{array}{r}-0.062 * \\
(0.008)\end{array}$ & $\begin{array}{c}-0.719 * \\
(0.097)\end{array}$ & $\begin{array}{c}-0.062 * \\
(0.008)\end{array}$ \\
\hline Number of observations & 19,554 & & 19,554 & \\
\hline Number of individuals & 5,303 & & 5,303 & \\
\hline Rho & $\begin{array}{c}0.301 * \\
(0.031)\end{array}$ & & $\begin{array}{c}0.301 * \\
(0.031)\end{array}$ & \\
\hline Log likelihood & -6273.493 & & -6273.502 & \\
\hline
\end{tabular}

Note: Standard errors in parentheses. The model also contains controls for year (seven dummies), civil status (four dummies), gender, age, age squared and a dummy for two jobs at the university. Reference groups of the variables in parentheses: number of working days (five), education $(\mathrm{PhD})$, type of career (teaching support)

* Significant at $5 \%$ 
Equation (3) implies, evaluated at the mean, that the average $\mathrm{MWP}_{\mathrm{x}}$ to reduce the commuting distance by one kilometre is $€ 0.490$ (s.e. 0.130 ), so $€ 0.245$ (s.e. 0.065 ) per kilometre travelled. ${ }^{16}$ Given an average commuting speed of $40 \mathrm{~km} / \mathrm{h}$, this corresponds to an average willingness to pay of about $€ 9.80$ to avoid 1 hour of commuting (with a standard error of 2.59 ), about $75 \%$ of the average net hourly wage.

It is plausible that this estimate predominantly refers to time losses. Usually, it is thought that monetary costs and the monetary value of the time losses are of the same magnitude (van Ommeren and Fosgerau 2009). However, at the university we focus on, workers who travel by public transport receive an imbursement between 50 and $70 \%$ of the travel expenses, so for these workers the costs predominantly refer to time losses. Also other workers with commutes that exceed $10 \mathrm{~km}$ receive a monetary reimbursement (up to $€ 60$ per month) and parking charges are quite small (less than $€ 1$ per day). Furthermore, for workers without any reimbursement, so for workers with distances up to $10 \mathrm{~km}$, it is likely that the majority of workers travel by bicycle, as this is the most common transport mode in the larger cities of The Netherlands for shorter distances. For bicycle users, the marginal monetary costs of travel are negligible.

We have tested this result using many alternative specifications. For example, we have tested if the disutility of commuting and the utility of wages vary among workers using a random coefficient specification (that is we let the coefficient of the wage and of the commuting distance to vary among workers). We found that the implied distribution of the coefficients is degenerate (has a variance very close to zero). We have also estimated models with other interactions and controls (e.g. weekly hours rather than daily hours; the logarithm of daily hours rather than daily hours), but this result remains robust.

The $\mathrm{MWP}_{\mathrm{x}}$ differs strongly between full-time and part-time workers, because of differences in the hours worked per day. For full-time workers, $\mathrm{MWP}_{\mathrm{x}}$ is 0.222 (with a s.e. of 0.059). The $\mathrm{MWP}_{\mathrm{x}}$ for workers on part-time jobs with 20 week hours per contract is almost twice as high: 0.396 (with a s.e. of 0.105). We have also estimated the model interacting both wage and the distance to the daily hours variable with part-time status. Both the interaction terms are far from statistically significant (with $t$ values of 0.25 and 0.70 respectively). Consequently, we are not able to detect any additional difference in the $\mathrm{MWP}_{\mathrm{x}}$ between part-time and full-time workers when accounting for the difference in the daily number of working hours.

We have also estimated models allowing for different impacts of wages and distance for faculty and non-faculty staff. We find that the effect of distance is somewhat higher for non-faculty workers. ${ }^{17}$ For non-faculty workers, $\mathrm{MWP}_{\mathrm{x}}$ equals 0.292 (s.e. 0.081), about $20 \%$ higher than the population-average $\mathrm{MWP}_{\mathrm{x}}$ reported above. The $\mathrm{MWP}_{\mathrm{x}}$ is statistically insignificant for faculty workers $\left(\mathrm{MWP}_{\mathrm{x}}\right.$ is equal to 0.062 with a standard error of 0.114 ), which prevents us from interpreting the $\mathrm{MWP}_{\mathrm{x}}$ for faculty workers. Nevertheless, the results indicate that their $\mathrm{MWP}_{\mathrm{x}}$ is (much) lower. This makes sense, because faculty members usually have much more flexibility with regard to teleworking as well as work start hours (compared to administrative positions), which is relevant to avoid peak congestion. Another issue is that it is plausible that faculty workers have been able to optimally choose their residence location conditional on the current workplace location, because they are less likely to quit the university for another position. As a result, it is plausible that these workers receive higher levels of compensation in the housing market.

\footnotetext{
16 Standard errors are calculated using the delta method. The average daily net wage is $€ 106$, daily work hours is 7.27 , and one-way commuting distance is $22 \mathrm{~km}$.

17 This finding also holds if we interact distance with educational level.
} 
Men and women usually experience different patterns of labour market transitions, so we have paid special attention to gender. We have re-estimated the models interacting wage and distance with gender. Using an average daily wage (distance) of $€ 99(38.74 \mathrm{~km})$ for women and of $€ 116\left(45.64 \mathrm{~km}\right.$ ) for men, we obtain a $\mathrm{MWP}_{\mathrm{x}}$ of 0.122 (s.e. 0.073) for men and of 0.675 (s.e. 0.183 ) for women. The difference in the $\mathrm{MWP}_{\mathrm{x}}$ across the gender dimension is substantial, 0.553 (s.e. 0.193), and statistically significant. These results indicate that, consistent with Van Ommeren and Fosgerau (2009), and a large labour market literature which shows that women react stronger to changes in the labour market than men, women have a higher $\mathrm{MWP}_{\mathrm{x}}$ to pay than men.

Control variables have the expected effects on the probability to quit. For example, career concerns are an important determinant of quitting decisions: recently promoted workers are less likely to quit and workers who have no promotion opportunities are more likely to quit. In addition, workers with a $\mathrm{PhD}$ are more likely to quit. We also find that the likelihood of quitting decreases almost linearly with the number of days worked. The probability to quit increases with the length of the working week, but the effect is only significant at $10 \%$ confidence level. Workers with two jobs at this organization are characterized by a lower likelihood of quitting. The effect of having a parking permit is not strong enough to be properly identified with our data. Workers commuting by public transport tend to quit less. This result makes sense when it is recognised that given short distances Dutch workers tend to use the bicycle whereas workers with long commutes who do not use public transport usually live at residence locations where the supply of public transport is poor, so they have to rely on the car, but as the highways close to the university are highly congested, these workers face an unusual inconvenient commute.

\section{Conclusion}

The current paper estimates the workers' willingness to pay for commuting using data from the personnel files of a Dutch university by means of a dynamic job search approach based on job quitting behaviour. So, we identify the willingness to pay using revealed preferences data, whereas the majority of studies rely on stated preferences (e.g., De Borger and Fosgerau 2008). The approach does not rely on the restrictive assumption of a competitive labour market with non-regulated wages, see Hwang et al. (1998), which does not apply to university workers. We do not control for residence location, so our estimates refer to the willingness to pay for commuting in addition to any compensation for commuting received in the housing market (e.g., lower house prices).

Our preferred estimate, robust to alternative model specifications, implies that the university workers' willingness to pay to avoid a $1 \mathrm{~km}$ increase in the length of the commute is $€ 0.25$. Given assumptions on speed, and noting that these workers hardly pay for monetary costs of travel, this suggests a cost of commuting time of about $75 \%$ of the workers' average (net) hourly wage. The cost is strongly decreasing in the number of daily hours worked in line with theory and is higher for non-faculty and female workers.

This study has clear implications for human resource managers (of universities) that aim to reduce job mobility. First, during the recruitment process, it may be useful to give priority to workers that live nearby (and are otherwise identical). In particular, workers that work few hours per day are more likely to quit if their commuting distance is long. Second, increasing wages for workers with long commutes strongly decreases job quitting, but this comes at a substantial cost for the employer. To fully compensate a worker for a $1 \mathrm{~h}$ oneway commute, the organisation we have focused on must increase wages by about $18 \%$. 
This is substantial. In addition, to compensate workers for long commutes would not be eco-friendly as it removes the incentive for workers with longer distances to decrease their commute. So, the eco-friendly human resource manager may only increase wages for those workers who do not come by car. An alternative route to reach a similar result is to charge workers for car parking and use the revenues to subsidise public transport.

Acknowledgments The views expressed in this paper are those of the authors and do not necessarily represent those of Cedefop. The usual disclaimer applies. We would like to thank three anonymous referees for useful comments.

Open Access This article is distributed under the terms of the Creative Commons Attribution License which permits any use, distribution, and reproduction in any medium, provided the original author(s) and the source are credited.

\section{Appendix}

See Table 2.

Table 2 Summary statistics

\begin{tabular}{|c|c|c|}
\hline & Mean & Standard deviation \\
\hline Quits & 0.124 & 0.330 \\
\hline Annual wage (thousand Euro) & 47.652 & 18.349 \\
\hline Log wage & 3.796 & 0.362 \\
\hline Commuting distance $(\mathrm{km})$ & 22.073 & 23.032 \\
\hline Log commuting distance & 2.684 & 0.970 \\
\hline No promotion opportunities & 0.704 & 0.456 \\
\hline Recent promotion & 0.109 & 0.312 \\
\hline Public transport & 0.255 & 0.436 \\
\hline Parking permit & 0.053 & 0.224 \\
\hline \multicolumn{3}{|l|}{ Job characteristics } \\
\hline Two jobs (at the organization) & 0.021 & 0.144 \\
\hline Number of weekly hours/38 & 0.829 & 0.234 \\
\hline Number of daily hours & 7.269 & 0.901 \\
\hline \multicolumn{3}{|l|}{ Number of working days } \\
\hline 1 & 0.035 & 0.184 \\
\hline 2 & 0.044 & 0.206 \\
\hline 3 & 0.107 & 0.310 \\
\hline 4 & 0.213 & 0.410 \\
\hline 5 & 0.601 & 0.490 \\
\hline \multicolumn{3}{|l|}{ Personal characteristics } \\
\hline Men & 0.603 & 0.489 \\
\hline Age & 45.493 & 10.260 \\
\hline Age squared (/100) & 21.748 & 9.240 \\
\hline \multicolumn{3}{|l|}{ Civil status } \\
\hline Married & 0.514 & 0.500 \\
\hline Living together & 0.141 & 0.348 \\
\hline
\end{tabular}


Table 2 continued

\begin{tabular}{lcl}
\hline & Mean & Standard deviation \\
\hline Single & 0.280 & 0.449 \\
Widow (er) & 0.008 & 0.089 \\
Divorced & 0.056 & 0.229 \\
Education & & \\
PhD & 0.328 & 0.470 \\
Master degree & 0.246 & 0.431 \\
No university degree & 0.426 & 0.495 \\
Job type & & \\
Teaching support & 0.166 & 0.373 \\
Faculty & 0.262 & 0.439 \\
Administrative & 0.572 & 0.495 \\
Number of observations & 19,554 & \\
Number of individuals & 5,303 & \\
\hline
\end{tabular}

\section{References}

Arnott, R.: Congestion tolling with agglomeration externalities. J. Urban Econ. 62(2), 187-203 (2007)

Barbezat, D.A.: Revisiting the seniority wage effect for faculty. Econ. Lett. 82(2), 289-294 (2004)

Dale-Olsen, H.: Estimating workers' marginal willingness to pay for safety using linked employer-employee data. Economica 73, 99-127 (2006)

De Borger, B., Fosgerau, M.: The trade-off between money and travel time: a test of the theory of referencedependent preferences. J. Urban Econ. 64(1), 101-115 (2008)

Gronberg, T.J., Reed, W.R.: Estimating workers' marginal willingness to pay for job attributes using duration data. J. Hum. Resour. 24, 911-931 (1994)

Gruetter, M., Lalive, R.: The importance of firms in wage determination. Labour. Econ. 16(2), 149-160 (2009)

Gutiérrez-i-Puigarnau, E., van Ommeren, J.N.: Start time worker compensation: implications for staggeredhours programs. J. Transp. Econ. Policy 46(1), 1-16 (2012)

Gutiérrez-i-Puigarnau, E., van Ommeren, J.N.: Labour supply and commuting. J. Urban Econ. 68, 82-89 (2010)

Gutiérrez-i-Puigarnau, E., van Ommeren, J.N.: Welfare effects of distortionary fringe benefits taxation: the case of employer-provided cars. Int. Econ. Rev. 52(4), 1105-1122 (2011)

Hwang, H.D., Reed, W.R., Hubbard, C.: Compensating wage differentials and unobserved productivity. J. Political Econ. 100(4), 835-858 (1992)

Hwang, H.D., Mortensen, D.T., Reed, W.R.: Hedonic wages and labour market search. J. Labor. Econ. 16(4), 815-847 (1998)

Isacsson, G., Swärdh, J.-E.: Empirical on-the-Job Search Model With Preferences for Relative Earnings: How High is the Value of Commuting Time? Working paper. Swedish National Road \& Transport Research Institute (VTI), Sweden (2007)

Manning, A.: The real thin theory: monopsony in modern labour markets. Labour Econ. 10, 105-131 (2003a)

Manning, A.: Monopsony in Motion. Princeton University Press, Princeton (2003b)

Parry, I.W.H., Bento, A.: Revenue recycling and the welfare effects of road pricing. Scand. J. Econ. 103(4), 645-671 (2001)

Ransom, M.R.: Seniority and monopsony in the academic labour market. Am. Econ. Rev. 83(1), 221-233 (1993)

Stutzer, A., Frey, B.S.: Stress that doesn't pay: the commuting paradox. Scand. J. Econ. 110(2), 339-366 (2008)

Van Ommeren, J.N., Van den Berg, G.J., Gorter, C.: Estimating the marginal willingness to pay for commuting. J. Reg. Sci. 40(3), 541-563 (2000)

Van Ommeren, J.N., Hazans, M.: The workers' value of the remaining employment contract duration. Economica 75(297), 116-136 (2008) 
Van Ommeren, J.N., Fosgerau, M.: Workers' marginal costs of commuting. J. Urban Econ. 65(1), 38-47 (2009)

Villanueva, E.: Estimating compensating wage differentials using voluntary job changes: evidence from Germany. Ind. Labor Relat. Rev. 4, 544-561 (2007)

Zax, J.S.: Compensation for commutes in labor and housing markets. J. Urban Econ. 30, 192-207 (1991)

\section{Author Biographies}

Giovanni Russo is a senior expert at CEDEFOP (European Centre for the Development of Vocational Education and Training). His research centers on (behavioral) labour economics, and focuses on firms' recruitment strategies and on the interrelationship between social norms and workers labour market behavior.

Jos van Ommeren is a Professor of Urban Economics at the VU University in Amsterdam, the Netherlands. His research focuses on the interrelationship between transport, labour and housing markets, with an emphasis on the economics of commuting as well as parking. He has published many articles within this field.

Piet Rietveld is a Professor in Transport Economics at VU University, Amsterdam. His work focuses on travel behavior, transport and climate change, transport policy and the interrelationship between transport and land use. 